\title{
FIM DOS PRINCÍPIOS CONTÁBEIS?
}

Luana Santos Mateo, Alessandra Michelle Chagas

Centro Universitário Antônio Eufrásio de Toledo, curso de Ciências Contábeis, Presidente Prudente, SP. E-mail: luanasantosmateo@hotmail.com

\section{RESUMO}

É de suma importância que o profissional da contabilidade esteja sempre atento às mudanças e atualizações que ocorrem, de maneira que as informações e demonstrações que forem elaboradas, respeitem a padronização internacional, a qual é obrigatória. $O$ objetivo deste estudo foi analisar o CPC 00 (NBC TG Estrutura Conceitual), que apresenta as diretivas que o profissional contábil tem como base para a elaboração das informações contábeis destinadas aos usuários internos e externos. A metodologia constou de pesquisa bibliográfica. Os resultados foram à importância que a revogação da Resolução CFC $n^{\circ}$ 750/93 trouxe à Contabilidade Brasileira, visto que atualmente os Princípios Contábeis estão inseridos no CPC, põe em conformidade as práticas internacionais. Concluímos que os Princípios Contábeis não foram extintos, mas sim, unificado ao CPC 00, que por sua vez rege de acordo com o padrão internacional.

Palavras-chave: Contabilidade, Estrutura, Informação Contábil, Padronização, Normas.

\section{END OF ACCOUNTING PRINCIPLES?}

\section{ABSTRACT}

It is of the utmost importance that the accounting professional is always aware of the changes and updates that occur, so that the information and statements that are elaborated, respect the international standardization, which is obligatory. The objective of this study was to analyze CPC 00 (NBC TG Conceptual Framework), which presents the policies that the professional that the accounting professional has as basis for the preparation of the accounting information intended for internal and external users. The methodology consisted of bibliographical research. The results were the importance that the revocation of CFC Resolution $n^{\circ} 750 / 93$ brought to the Brazilian Accounting, since the Accounting Principles are currently included in the CPC, it complies international practices. We conclude that the Accounting Principles were not extinguished, but rather, unified to CPC 00, which in turn rules according to the international standard.

Keywords: Accounting, Structure, Accounting Information, Standardization, Standards.

\section{INTRODUÇÃO}

As relações comerciais sofrem constantes alterações devido à forma como os mercados se comunicam no mundo globalizado. Não há mais fronteiras no mundo dos negócios. As mercadorias não são mais comercializadas de forma regional, mas sim internacional. Um produto que é comercializado no Japão pode facilmente ser adquirido por consumidor brasileiro.

Se a forma de negociação já não é mais a mesma, a Contabilidade, considerada a linguagem mundial dos negócios, também deve sofrer atualizações. Em um mercado cada vez mais competitivo, necessário se faz que as empresas busquem informações econômico-financeiras sobre seus concorrentes. Logo, utilizam-se da Contabilidade na coleta destas informações.

No mundo moderno, analisar as demonstrações contábeis dos concorrentes torna-se um fator de grande importância no quesito sobrevivência das empresas no mercado. Porém esta análise é dificultada quando não se possuem normas semelhantes entre as diversas nações nas 
quais estas empresas estão instaladas. Como comparar o desempenho de uma empresa norteamericana com uma empresa brasileira se as regras para elaboração das informações contábeis são divergentes?

Visando dirimir estas diferenças, a Contabilidade iniciou uma remodelagem em suas normas, contando com a ajuda de organismos internacionais. Em busca de uma aproximação das práticas contábeis entre os países, normas internacionais de contabilidade, denominadas International Financial Reporting Standards (IFRS), são editadas pelo International Accounting Standards Board (IASB), que servem de parâmetro na confeç̧ão de normas contábeis para os países no mundo todo.

Buscando adequar-se aos padrões internacionais, a Contabilidade Brasileira, desde 2008, passa por grandes transformações, o que requer atualização constante dos profissionais da área contábil. Neste processo, a estrutura conceitual das Ciências Contábeis sofreu alterações.

O objetivo deste estudo foi analisar o Pronunciamento Contábil, denominado CPC 00, que trata das instruções que o contador deve ter como base na elaboração das demonstrações contábeis. Analisa-se o atual arcabouço da contabilidade no Brasil e problematiza-se a importância do conhecimento desta Norma ao profissional da contabilidade.

\section{METODOLOGIA}

A metodologia utilizada para a pesquisa concentrara-se em pesquisa bibliográfica, extraídas de sites que regulamentam as Normas Contábeis Brasileiras, tais como Conselho Federal de Contabilidade (CFC), Conselho Regional de Contabilidade (CRC), Comitê de Pronunciamentos Contábeis (CPC), resoluções normativas, bem como, em livros que tratam da Teoria da Contabilidade.

\section{RESULTADOS}

Constatou-se que é foi essencial a revogação da Resolução CFC $n^{\circ} 750 / 93$, já que a união da mesma ao CPC 00 fundiu-se em apenas uma normativa, e mais importante ainda, agora caminham de acordo com as práticas internacionais estabelecidas, havendo harmonização entre os países.

\section{CONCEITO E OBJETIVO DA CIÊNCIA CONTÁBIL}

A contabilidade é uma ciência social. A princípio, muitos acreditam, ao se depararem com números, cálculos e fórmulas, que ela é uma ciência exata. Entretanto as Ciências Contábeis, mesmo se utilizando da Matemática, Estatística, dentre outros métodos quantitativos, avalia o impacto da ação do homem sobre o patrimônio (conjunto de bens, direitos e obrigações). A contabilidade caminha conjuntamente com a Ciência Econômica e com a da Administração, envolvida na casa do saber humano denominado de Ciências Sociais Aplicadas.

A contabilidade vem com intuito de estudar o patrimônio e produzir informações cruciais para a tomada de decisão dentro das organizações, seja para usuários externos e internos da mesma.

De acordo com Marion (2009, p. 28), "A Contabilidade é o instrumento que fornece o máximo de informações uteis para a tomada de decisões dentro e fora da empresa. Ela é muito antiga e sempre existiu para auxiliar as pessoas tomarem decisões. "

As movimentações geradas dentro da empresa são transformadas em relatórios, que consequentemente são analisadas em três momentos distintos: situação atual, eventos passados e possíveis eventos da empresa. Tudo isso pode ser comparado entre os mesmos, resultando em uma tomada de decisão aperfeiçoada.

\section{EVOLUÇÃO DA CONTABILIDADE}


A contabilidade existe desde a época onde não se existiam pecúnias, números ou escritas. Segundo ludícibus (2005) a Contabilidade é tão antiga quanto o próprio homem que pensa.

Na Bíblia Sagrada, vê-se o zelo na questão do controle de seu patrimônio pessoal. No livro de Jó 1,3, "Possuía também sete mil ovelhas, três mil camelos, quinhentas juntas de boi, quinhentas mulas e grande número de empregados. Jó era o mais rico dos homens do Oriente."

Observa-se que mesmo sem existir números, a contabilidade já era utilizada para a finalidade de controle patrimonial ou controle de inventario. Nesta etapa, é possível classificá-la como uma fase empírica, onde as figuras e desenhos eram quem identificavam o patrimônio existente.

Com o transcorrer dos anos e o desenvolvimento da sociedade e das organizações, a contabilidade também necessitou de um desenvolvimento científico, devido à preocupação em apresentar de forma mais consistente os conceitos, expressões e medidas a serem tomadas.

Antigamente, as formas de negócio eram simples, porém, com a ampliação do volume de recursos envolvidos, o acréscimo no número de empresas, dentre outras transações, fez-se necessário a criação de procedimentos contábeis, para que fosse minimizado as divergências criadas.

A ideia de criar princípios que norteassem a dissipassem essas divergências ocorreu nos EUA, em 1930. De acordo com ludicibus, Marion e Faria (2009, p. 64):

A emissão de pronunciamentos sobre Princípios de Contabilidade para orientação dos contadores no exercício da sua profissão teve início nos Estados Unidos, na década de 30, após a quebra da Bolsa de Nova lorque. Ficaram conhecidos como Princípios Contábeis Geralemnet Aceitos PCGAs, ou como uma sigla muito conhecida por empresas multinacionais, os famosos "GAAPs". Desde então, houve uma maior preocupação com a informalização de Princípios que pudessem dar embasamento às normas e regras contábeis.

Com isso, foi possível obter uma convergência de entendimentos sobre as práticas contábeis, e estabelecimento de regras a serem acatadas por todos, com intuito de dar uniformidade e harmonia a ciência contábil.

\section{CONTABILIDADE BRASILEIRA NA ATUALIDADE}

Atualmente, a contabilidade brasileira almeja adequar-se às normas internacionais, para que fique em harmonia às práticas adotadas em outros países. Os órgãos reguladores e conselhos da classe contábil emitem normas e códigos para que haja um padrão. Dá-se então, a necessidade da padronização das normas.

Buscando o alcance de tal aproximação das normas internacionais, em 2008 foi editada a Lei $n^{\circ} 11.638$, que trouxe significativas mudanças para a contabilidade brasileira. Outro fator que contribuiu de forma significativa foi a criação do Comitê de Pronunciamentos Contábeis (CPC), órgão independente que tem por objetivo emitir normas contábeis brasileiras que sejam convergentes com as internacionais, buscando a centralização e uniformização de emissão destas.

As normas editadas pelo CPC possuem como base as Normas Internacionais de Contabilidade, emitidas pelo IASB, traduzido para o português, Conselho de Normas Internacionais de Contabilidade. O IASB é quem emite as normas internacionais, denominadas IRFS, International Financial Reporting Standards, que traduzido na língua portuguesa significa Normas Internacionais de Informação Financeira, que constituem um conjunto de normas internacionais de contabilidade, que visam padronizar os procedimentos contábeis, conjuntamente as políticas existentes entre os países, melhorando a estrutura conceitual e proporcionando a mesma interpretação das demonstrações financeiras no mundo todo. 


\section{ESTRUTURA CONCEITUAL BÁSICA DA CONTABILIDADE NO BRASIL}

As normas internacionais de contabilidade foram introduzidas no Brasil em 2008, com a promulgação da lei 11.638/07. A partir deste ano, as regras contábeis brasileiras passam por significativas mudanças. Isto devido a necessidade de adequação de regramentos já existentes aos padrões internacionais. Por consequência, o arcabouço teórico das Ciências Contábeis no Brasil também sofreu alterações.

Em 2008, o CPC emitiu o pronunciamento CPC 00, intitulado de Estrutura Conceitual Básica para elaboração e divulgação do relatório contábil de propósito geral. Segundo o Comitê de Pronunciamentos Contábeis, finalidade do CPC 00 é estabelecer conceitos que fundamentam as demonstrações contábeis. Este CPC é a base para todos os outros CPCs, pois é ele quem auxilia os profissionais de contabilidade, dita regras para que haja harmonização e colaboração para que os usuários interpretem as informações da forma mais clara e coesa possível.

A estrutura conceitual básica da contabilidade brasileira torna-se, a partir deste momento, regida por duas legislações básicas: Resolução do Conselho Federal de Contabilidade (CFC) n. 750/93, a qual trata dos Princípios de Contabilidade, e o CPC 00.

\section{PRINCÍPIOS CONTÁBEIS E A ATUAL ESTRUTURA CONCEITUAL BÁSICA}

A Resolução do Conselho Federal de Contabilidade (CFC) n. 750/93, dispõe dos Princípios de Contabilidade (PC), que anteriormente era nomeado como os Princípios Fundamentais de Contabilidade (PFC). A resolução foi revogada. Entretanto, é importante ressaltar que mesmo com a revogação os princípios ainda necessitam ser considerados no exercício da profissão contábil, e constitui condição legítima das Normas Brasileiras de Contabilidade (NBC).

Os princípios contábeis têm por objetivo principal informar e nortear usuários da informação contábil com conceitos básicos e normas fundamentais, as quais guiam o profissional na elaboração e apresentação de tais informações. De acordo com ludícibus (2002), eles são conceitos básicos que constituem o núcleo essencial que deve guiar a profissão na consecução dos objetivos da Contabilidade, que consistem em apresentar informação estruturada para os usuários.

Segundo a Resolução n.o 750/93, os princípios contábeis são: Entidade, Continuidade, Oportunidade, Registro pelo Valor Original, Atualização Monetária (revogado pela Resolução CFC n.o 1.282/10), Competência e Prudência.

\section{A ATUAL ESTRUTURA CONCEITUAL BÁSICA DA CONTABILIDADE BRASILEIRA}

Revogada a partir de 01/01/2017 pela NBC TSP ESTRUTURA CONCEITUAL, conforme publicação do DOU de 4/10/2016, Seção 1, e o CPC 00, emitido pelo comitê de pronunciamentos contábeis, a resolução CFC $n^{\circ} 750 / 93$ deixou de fazer parte da Estrutura Conceitual Básica da Contabilidade Brasileira.

A partir de 2017, então, os profissionais da área contábil possuem por norteador apenas o CPC 00. Entretanto, isto não significa o fim dos princípios de contabilidade, mas uma evolução da Ciência no Brasil.

Apesar da revogação da Resolução CFC $n^{\circ} 750 / 93$, os princípios contábeis ainda existem, contudo inseridos no CPC 00. Presente na norma, eles sofreram adequações a fim de atender aos requisitos da padronização internacional, mudando sua nomenclatura que antes era de 'Princípios Fundamentais da Contabilidade' para 'Princípios da Contabilidade', excluindo-se o termo 'fundamentais' por não possuir mais sua essência voltada apenas a usuários do Brasil, mas sim, parametrizada de forma a ser aceita internacionalmente.

Uma das principais mudanças trazidas por este Pronunciamento Contábil foi a retirada do princípio da Prudência, visto que ele não consta atualmente no CPC 00. Esta retirada se deu ao fato de que, este princípio trazia a ideia de um pessimismo, onde o profissional da contabilidade, 
para reconhecimento de valores no ativo e passivo, trataria como uma forma de precaução o ativo com um valor menor e o passivo com um valor maior (princípio da prudência). Porém, nem sempre esta forma de tratamento contábil transmite a veracidade e fidedignidade da informação apresentada, afetando a interpretação dos usuários das demonstrações. Os demais princípios permanecem inalterados e válidos.

\section{CONCLUSÃO}

Devido à alteração na relação consumidor versus empresa, o mercado está cada vez mais competitivo. Com a globalização, não há mais barreiras entre os comércios, sendo que o consumidor tem acesso fácil para adquirir mercadorias de países distintos. Com isso, a ciência contábil tornou-se ainda mais importante aos negócios, visto que, faz-se necessário a análise de dados econômico-financeiros dos concorrentes, sendo uma questão de sobrevivência.

A ciência contábil, assim como toda ciência, é regida por normas que devem ser atendidas por todos os profissionais que nela atuam. Esta por sua vez, é a linguagem mundial dos negócios, é de extrema importância que as regras praticadas entre os países sejam, no mínimo, semelhantes, não distorcendo a realidade econômico-financeira quando se compara os dados apresentados por empresas localizadas em diferentes nações.

Se as regras a serem seguidas fossem redigidas da maneira como cada país optasse, no momento de uma transação internacional os valores seriam discrepantes e não se teria uma base para mensuração. Por exemplo, no momento da consolidação de Balanço Patrimonial entre uma controlada e sua controladora, duas pessoas jurídicas devem se fundir em apenas uma nova personalidade jurídica para fins da consolidação. Se não existisse padronização entre os países, não seria possível verificar a veracidade e fidedignidade das informações.

Assim, as normas internacionais de contabilidade editadas pelo IASB são de grande auxilio, já que os países podem elaborar suas normas tendo por base estes.

Importantes avanços rumo a aproximação das práticas contábeis às internacionais foram inseridos no contexto da contabilidade brasileira. A revogação da resolução CFC 750/93 é uma delas. Em um primeiro momento, pode-se pensar que isto representa um retrocesso à contabilidade enquanto ciência, já que perde parte de sua estruturação teórica. Entretanto, isto significa um avanço à Ciência Contábil, visto que com a revogação de tal normativo, intercorre a aproximação das práticas contábeis internacionais, tornando-as mais efetivas, isto porque o CPC 00 é elaborado tendo por base uma norma internacional, porém os princípios de contabilidade não.

Por fim, não se pode falar na morte dos princípios na contabilidade brasileira, já que de fato não houve revogação de legislação, mas sim unificação e atualização da estrutura conceitual da contabilidade brasileira aos padrões internacionais, tendo em vista que o CPC 00 absorveu muitos dos preceitos contidos na resolução CFC 750/93.

\section{REFERÊNCIAS BIBLIOGRÁFICAS}

CFC. Conselho Federal de Contabilidade. Disponível em: <http://cfc.org.br/tecnica/normasbrasileiras-de-contabilidade/> Acesso em 20 mai. 2017.

COELHO, C.; LINS, L. Teoria da Contabilidade. Abordagem Contextual Histórica e Gerencial. São Paulo: Atlas, 2010.

COMITÊ DE PRONUNCIAMENTO CONTÁBEIS. CPC 00 (R1) - Estrutura Conceitual para Elaboração e Divulgação de Relatório Contábil-Financeiro. Disponível em: <http://www.cpc.org.br/CPC/Documentos-Emitidos/Pronunciamentos/Pronunciamento?ld=80> Acesso em 14 mai. 2017. 
IUDÍCIBUS, S.; MARION, J.; FARIA, A. Introdução à Teoria da Contabilidade para o Nível de Graduação. 5.edSão Paulo: Atlas, 2009.

MARION, J. Contabilidade Básica. 10.edSão Paulo: Atlas, 2009.

NIYAMA, J; SILVA, C. Teoria da contabilidade. 3.edSão Paulo: Atlas, 2013. 